\title{
RISK ASSESSMENT IN SMALL AND MEDIUM ENTERPRISES IN THE SLOVAK REPUBLIC \\ Denisa Janasová ${ }^{1}$, Stanislava Strelcová ${ }^{2}$
}

\begin{abstract}
The analysis and evaluation of risks are a decisive part of risk assessment in the risk management framework. Based on the results of the analysis and risk evaluation we can classify the risks as acceptable and unacceptable ones and subsequently manage them. The small and medium enterprises pay the analysis and risk evaluation the lowest attention. In our opinion this is linked with failing to utilise exact methods which seem to be complicated for their practical utilisation. They are not used especially for analysing and evaluating the risks which have their basis in epistemic uncertainty. The professional community has been discussing epistemic uncertainty for a long time. This assumption is valid mainly in the SMEs which have no competent person on the one hand and a shortage of information concerning the area assessed on the other hand. The main goal of this article is to assess the current state of implementing the process of analysing and evaluating the risk in the SMEs and to define the main problems from a questionnaire research carried out in 2017 in which 485 SMEs working in Slovakia took part. On the base of the conducted research, we can state that in spite of the fact that only highquality risk assessment leads the companies to take suitable measures for risk reduction, the companies pay unadequate attention to the analysis and risk evaluation.
\end{abstract}

JEL Classification Numbers: M21, R12, G32; DOI: http://dx.doi.org/10.12955/cbup.v6.1158

Keywords: risk management, risk assessment, risk analysis, risk evaluation, survey research, Slovak enterprises

\section{Introduction}

Risk assessment is an important part of risk management which lists acceptable and unacceptable risks. On the basis of this list, companies take measures to mitigate unacceptable risks. Unfortunately, a lot of companies assess the risks intuitively or with lack of information. These companies perform risk assessment inconsistently or in the form of a rough estimation.

The main goal of this article is to assess the current state of implementing the process of analysing and evaluating the risk in the small and medium enterprises in Slovakia and to define the main problems on the basis of a questionnaire carried out in 2017. The questionnaire contained questions about the implementation of risk analysis and assessment in SMEs. Basic methods of statistical assessment were used, namely simple classification of statistics and calculations of relative countability.

\section{Risks Assessment in Enterprise}

Risk management is a process aimed at assessing and managing the risks with the goal to minimise the losses and maximise the opportunities, i.e. a risk is a potential loss or a potential chance. The essence of risk management is to reveal and to reduce the risks purposefully. The risk management process consists of several basic steps (phases). The risk management process is described in the professional literature in various ways. According to Šimák (2006) it contains two basic phases. Zapletalová et al. (2012) divides them into three phases (identifying the risks, analysing and evaluating the risks, treating the risks). Some publications (Kafka et al., 2009; Mikušová et al., 2014) state that the risk management process contains four phases and according to ISO STN 31000 Risk Management and the Australian standard 4360:2004 it consists of five basic steps. These differences consist in a different classification of the activities into individual phases and steps. The content and essence of the individual activities as well as their accessibility is the same in all of the aforementioned sources. This article will be based on classifying the risk management process into two basic phases, i.e. the assessment and management of the risks. In the framework of risk assessment we analyse the internal links and their importance for the whole. Subsequently the identification, analysis and evaluation of the risks are carried out. The phase of the risk management consists of reducing the risks, informing the concerned and competent persons with the residual risks and monitoring (checking) the risks (Šimák, 2006).

The activities carried out in the framework of risk assessment are aimed at understanding the relations and links between the elements of the system being assessed and this enables a simpler identification of the possible threats. The subsequent risk analysis investigates the essential properties and factors of the risk with an emphasis on the likelihood of developing a negative event and consequences it can cause. Risk evaluation is the last step in the framework of assessing risks (Šimák, 2006). The output of

\footnotetext{
${ }^{1}$ Faculty of Security Engineering, University of Žilina, denisa.janasova@gmail.com.

${ }^{2}$ Faculty of Security Engineering, University of Žilina, stanislava.strelcova @ fbi.uniza.sk.
} 
the risk evaluation is a list of acceptable and unacceptable risks and it is a basis for realising the risk treatment. We can say that data with various information values is the input and the selection of the unacceptable risks we have worked primarily with is the desired output. Based on the importance of the risks the decisions about risk management are subsequently taken. Šimák (2006) says some professional sources do not differentiate the analysis and evaluation of the risks during the risk assessment phase, others consider them to be independent activities. This author recommends distinguishing the analysis and evaluation from both the terminological and content point of view.

According to the STN ISO 31000 the analysis contains "considerations about the causes and sources of the risk". The identification of the factors resulting from the consequences of a negative event and the likelihood of its development (the causes and sources of the risks), their evaluation and the subsequent definition of the risk extent is carried out in the framework of the risk analysis. The risk evaluation is aimed at comparing the size of the analysed risks between themselves as well as with the stated level of the unacceptable risks. In some cases, the assessed risks can be analysed again. The risk evaluation determines the risks we have to deal with or to manage. The output of the evaluation is the creation of the risk list and their classification into the acceptable and unacceptable ones. The realisation of analysing and evaluating the risks is identically understood in the Australian standard 4360:2004. The structure of the risk management according to COSO ERM was created regarding to the requirements of the standard ISO 31000 (Curtis et al., 2012). In spite of this it makes no difference between the activities of the analysis and evaluation. The main goal and perhaps also the sense of the risk assessment phase is first of all being aware of all risks which threaten the planned activities and providing support for making decisions in the risk management phase.

The international research Treasury Risk Survey aimed at the company risk management says that for the majority of the companies the risk management goal is to minimise their negative influence on the economic results. The companies are aware of the necessity of risk management and they orient themselves especially on the internal inspections and changes of the processes in an effort to minimise risk. At the same time the survey also indicates that a difficult market situation forces even smaller companies to pay attention to risk management. In the majority of enterprises, risk management is centralised on the top management level (Globálne, 2013).

Several surveys dealing with entrepreneurial risk management have been carried out in Slovakia. We consider the research of the SMEs in 2016 (Klučka \& Grünbichler, 20016) to be very incentive. The research determined that only a negligible part of the addressed SMEs had a person responsible for the risk management or a department created in the company for this purpose. Except for this, no exact techniques are used for defining the risk and the estimation is only of an intuitive character, the owners rely on their empirical knowledge. For this reason, a significant part of the SME owners or the managers do not know the exact techniques, or they consider them to be too complicated for any practical utilisation.

\section{Data Description and Methodology}

A questionnaire survey aimed at the risk management in the SMEs in Slovakia was carried out in 2017. This research was part of the project VEGA 1/0560/16 Risk Management of SMEs in Slovakia as Prevention of Company Crises. The questionnaires asked the companies about the real state of implementing the processes of analysing and evaluating the risks. 485 companies (314 microcompanies, 114 small and 57 medium enterprises) took part in the survey. The basic methods of the statistic assessment for presenting the determined facts from the questionnaire research were used. The simple classification of the logogram, the classification according to two or three statistical signs and calculation of relative quantity belong to these methods.

The basic questionnaire question dealt with an activity which is emphasised in the framework of the risk management. The answers to this question represent the basic idea of this article. This question was as follows: Which of the main risk management activities do you pay the biggest attention to? The following answers were available:

- identifying the risks,

- analysing the risks (defining the likelihood and consequence),

- evaluating the risks (stating the risks' seriousness),

- creating measures to reduce the risks, 
- all activities are paid the same attention,

- none of these activities.

Based on the fact the companies pay the lowest attention to the analysis and evaluation of risks, this article aims especially at these two risk assessment activities. The following simplified conclusion can be derived - the risk analysis and evaluation are complicated activities from the point of view of time and expertise. The companies satisfy themselves only with a simplified risk assessment and they pay attention (according to their opinion) to "more important" activities. The article investigates how the companies define the size of the risk. The determined size of the risk is an assumption for defining their importance where the decision about the acceptability or non-acceptability of the risk depends on the defined level of tolerance to the risks. Therefore, we investigated if the border of risk acceptability is stated in the companies.

In 2016 in Slovakia, micro-companies consisted of $97.1 \%$, small enterprise $2.3 \%$ and medium enterprises $0.5 \%$ of companies (Malé, 2017). This representation of the Slovak companies shows (regarding to the questionnaire survey) the basic statistical file. $65 \%$ of the micro-companies, $24 \%$ of the small enterprises and $12 \%$ of the medium enterprises took part in the survey. The percentage of companies according to their size is in the representation sample of the questionnaire adequate regarding the percentage of enterprises in the basic statistical file. Therefore, we can generalise the determined conclusions for the whole entrepreneurial environment.

\section{Results}

The activities carried out in the framework of analysing and evaluating risks are closely connected. As we mentioned in the previous part of the article, some professional publications do not distinguish the activities carried out in the framework of risk analysis and evaluation. The questionnaire survey determined that the lowest attention is paid to evaluating, monitoring and analysing risks (Figure 1). The percentage representation of the companies according to the activities they pay the highest attention to during risk management regarding and regardless to their size is approximately the same. The largest differences can be recognised in the area of monitoring risks. Risk monitoring is preferred by twice as many companies (the external circle - Figure 1) compared to all enterprises regardless to their size (the internal circle - Figure 1) or with micro-companies and small enterprises (the second and third circle - Figure 1). The further presentations of the research results do not consider the companies' sizes.

The internal circle in Figure 1 depicts the relative quantity of the companies (regardless to their size). It shows which of the risk management activities is paid the greatest attention to. The results show that $25 \%$ of the addressed companies do not deal with risk management. If we compare this status with the second, third and fourth circle in Figure q (classification of the companies according to their size) we can say that especially the micro-companies and small enterprises do not deal with risk management. The micro-companies and small enterprises perceive risk management as another administrative burden and do not see any reason to realise it. In spite of this fact the survey shows that $75 \%$ of the addressed companies deal with risk management and $24 \%$ of the enterprises cover all risk management activities. We can say these enterprises realise risk management in a continual way. But there is majority of companies that prefer only some of these activities. The companies predominantly orient on identifying risks and on creating measures for their reduction. The lowest attention is paid to risk evaluation except for small enterprises which deal with the risk monitoring at the lowest level.

The values of the risks are not defined by $48 \%$ of the addressed companies (see the Figure 2). We assumed that approximately $25 \%$ of the companies would not define the value of the risk as this proportional representation is created by those companies that do not deal with risk management (see the Figure 1). Those companies that stated they did not deal with risk management do not evaluate risks. Out of the remaining $23 \%$ of the companies that do not define the values of risks (after excluding $25 \%$ of the companies which do not deal with risk management at all) $16.5 \%$ of the companies say they deal with all Risk management activities and with the creation of measures for reducing risks. The remaining $6.5 \%$ of the companies that do not state the size of the risk prefer either the identification, analysis, evaluation or risk monitoring in risk management. 

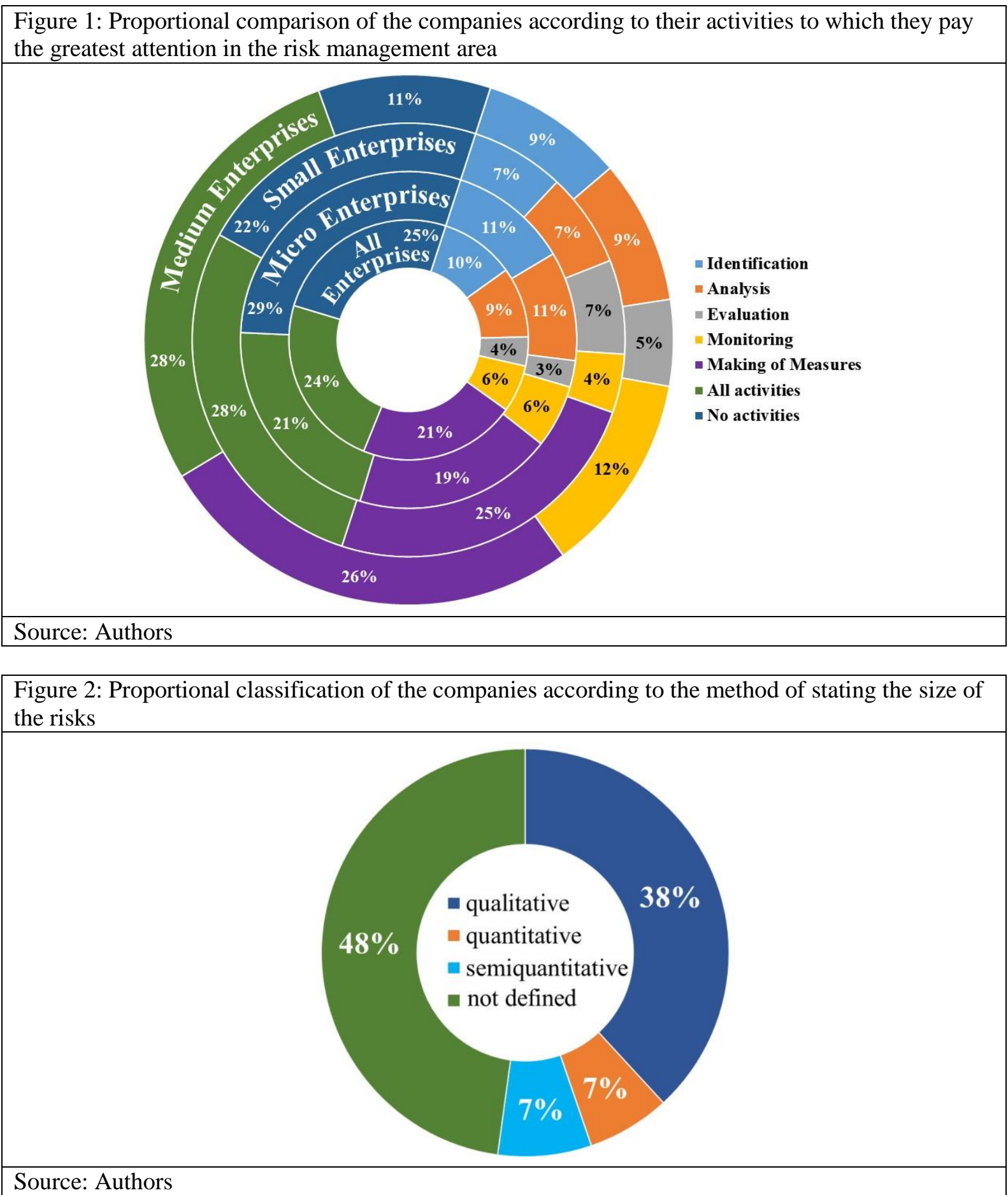

When stating the size of the risk we implement especially the qualitative expression in the form of a verbal description (e.g. small, medium, big risk). $38 \%$ of the companies define the risk size in this way. Only a small part of the addressed companies states the size of the risks either quantitatively through expressing the risk in a mathematical or statistical way or semi-quantitatively, verbally by attaching the point value. This determination of risks is also used by $7 \%$ of the enterprises. The comparison of enterprises according to the classification of their preferred activities on risk management and the risk evaluation method shows that qualitative, quantitative and semi-quantitative risk evaluation is used by the companies approximately on the same level. We cannot say whether 45 $\%$ of the companies that define the risk value qualitatively or semi-qualitatively carry out this analysis by using the method of risk assessment or they only rely on intuitive estimation. This is another challenge for the investigation. The companies utilising the mathematical and statistical expression of the risks are expected to use these methods and techniques. 
The stating of the risk rate is the output from the risk analysis and input from evaluating the risks. The risk evaluation compares the risk rate with the defined acceptability level and prioritises the risks. Before analysing and evaluating the risks, it is necessary to determine the boundary of the risk acceptability. The stating of the risk acceptability is an important assumption for risk evaluation. Therefore, the next research dealt with the question of if the companies stated the boundary of risk acceptability.

Figure 3: Proportional comparison of the companies according to the method of stating the risk rate and boundary of risk tolerance

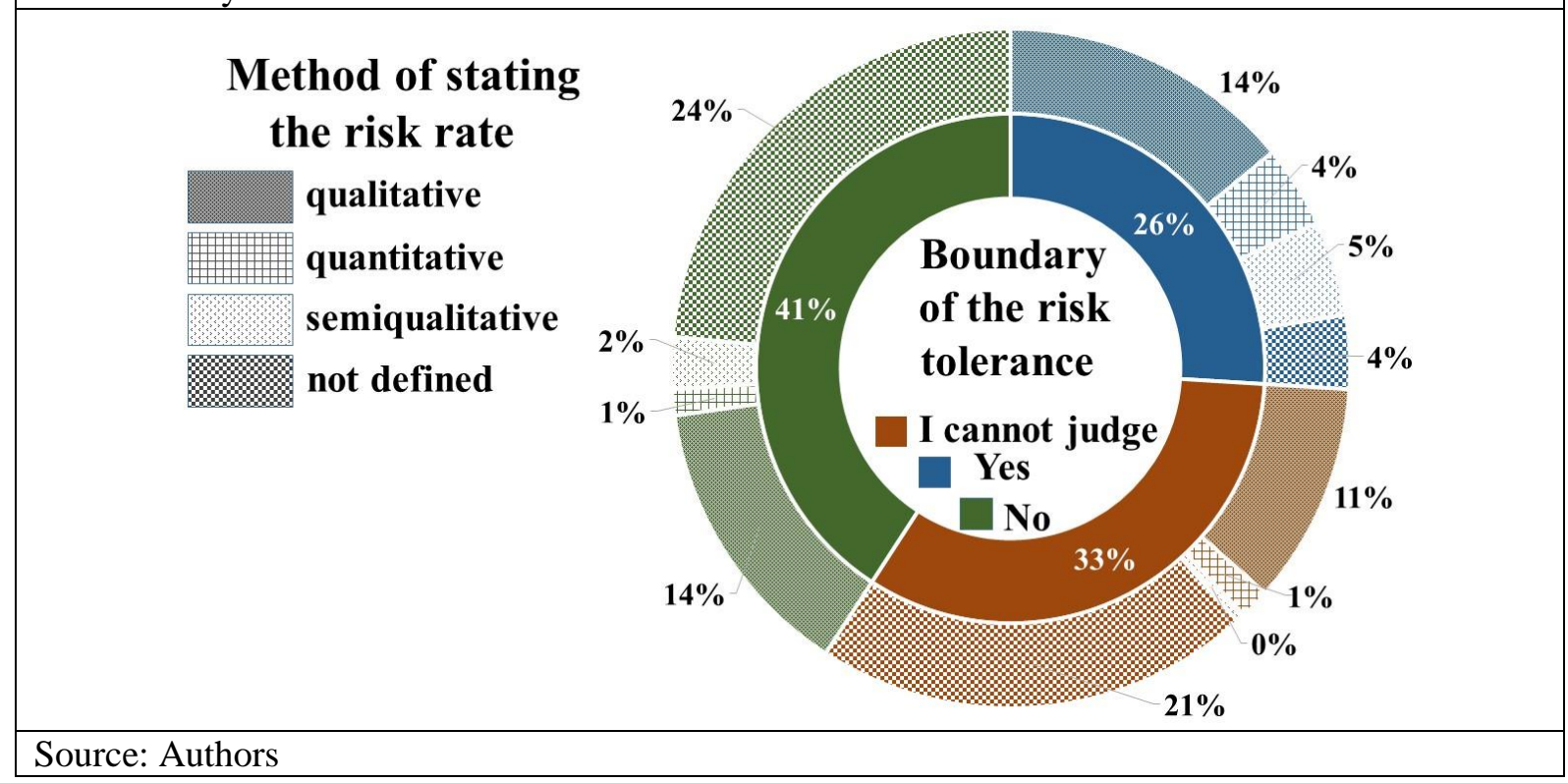

It was determined that $41 \%$ of the companies had not stated the level of risk tolerance and $33 \%$ could not say if their answer was a yes or no. The companies with defined boundary of the risk acceptability are the least represented here $-26 \%$ (see the internal circle, Figure 3). No surprising conclusions were found (Figure 3) by comparing the companies classified according to the method of stating the risk size and the existence of the risk tolerance level. The companies that do not state the risk rate prevailingly do not define the level of the risk tolerance or are not able to assess if they determine this level. The companies that do not state the risk size (the external circle, Figure 3) are minimally represented just from the point of view of stating the level of the risk tolerance (the internal circle, Figure 3). These companies consist of only $4 \%$. This leads to the conclusion that a predominant majority of the companies which stated the level of the risk tolerance determined also the risk size (qualitatively, quantitatively or semi-quantitatively). On the contrary, the companies that do not determine the risk value and the level of the risk tolerance have the strongest representation $-24 \%$ of the companies.

We can say that the companies utilise only some activities of the risk management according to their needs, i.e. the risk management is not used continually. Some companies pay the same attention to all risk management activities, however, at the same time they say they do not state the risk size or do not determine the boundary of risk acceptability. Those are the two main assumptions for analysing and evaluating risks. Risk analysis and evaluation are activities the companies pay the least attention to in spite of the fact that only on the basis of high-quality risk assessment an enterprise is able to take suitable measures for risk reduction.

\section{Conclusion}

Due to permanent changes in the entrepreneurial environment, the influence of competitive surroundings, and the consequences of the economic crises, a large percentage of SMEs have increased their interest in the risk management. Several investigations (Klučka \& Grünbichler, 2016; Beasley et al, 2016) and studies (Šimák, 2006; Ahmed \& Manab, 2016; Cho, 2015; Hosseini et al, 2016) shown the barriers of effective risk management performance. The research results show the increased interest of SMEs in risk management. However, there is still the question if risk management is really utilised in the enterprises or if it is only a marketing move. We can discuss the 
question whether mentioning the term risk management by the SMEs is not only an attempt to improve their reputation or a shallow follow up of the risk management trends which have come to the foreground recently.

Risk management in SMEs is conducted on a voluntary basis. Based on the findings it is possible to claim it is not ensured continually. Even in spite of the fact that the awareness of the danger itself does not reduce this risk it is not suitable to assess and manage the risks only on the basis of intuition or rough estimations or to be limited only on identifying the sources of the risks without any risk analysis or evaluation. The research results aimed at assessing the risks in companies showed the necessity and substantiality of their solution. We consider it important to aim especially at utilising the methods and techniques during stating the size of risks which are simple for the implementation in the enterprises. Last but not least, appropriate attention should be paid to stating the level of the risk tolerance for a company.

\section{Acknowledgements}

This paper was created with the support of the projects VEGA 1/0560/16 Risk Management in SMEs in the Slovak Republic - Prevention of Corporate Crisis and IGP 201706 Analysis and Evaluation of Business Risks as Part of the Risk Management Process.

\section{References}

Ahmed, I. \& N. A. Manab. (2016). Influence of Enterprise Risk Management Success Factors on Firm Financial and Nonfinancial Performance: A Proposed Model. In: International Juornal of Economics and Financial Issues. Vol. 6, Iss. 3, p. 830836. ISSN: 2146-4138

Beasley, M. et al. (2016). The State of Risk Oversight: An Overview of Enterprise Risk Management Practices. [Web blog post]. Retrieved from https://erm.ncsu.edu/az/erm/i/chan/library/AICPA_ERM_Research_Study_2016.pdf

Curtis, P. et al. (2012). COSO: Risk assessment in practice. Deloitte \& Touche LLP. [Web blog post]. Retrieved from https://www2.deloitte.com/content/dam/Deloitte/global/Documents/Governance-Risk-Compliance/dttl-grcriskassessmentinpractice.pdf

Globálne trendy v riadení podnikových rizík. (2013). CFO Best Practice: Zdroj informácií pre finančné riadenie podnikov. [Web blog post]. Retrieved from http://www.cfo.sk/articles/globalne-trendy-v-riadeni-podnikovych-rizik\#.WJg6jNLhDcs

HB 436:2004 - Handbook Risk Management Guidelines Companion to AS/NZS 4360:2004

Hosseini, M. R. et al. (2016). Critical success factors for implementing risk management systems in developing countries. Construction Economics and Building, 16(1), 18-32, 2016. [Web blog post]. Retrieved from http://dx.doi.org/10.5130/AJCEB.v16i1.4651

Cho, E. (2015). Exploring Barriers to Effective Risk Management Trough a Proposed Risk Governance Framework.

Dissertation: Georgia State University. [Web blog post]. Retrieved from https://scholarworks.gsu.edu/bus_admin_diss/60/

ISO STN 31000: 2011. Manažérstvo rizika - Zásady a návod

Kafka, T. (2009). Průvodce pro interní audit a risk management. Praha: C. H. Beck. ISBN 978-80-7400-121-5

Klučka, J. \& R. Grünbichler. (2016). Risikomanagement: Vebreitung, Bedeutung und zukünftige Erwartungen: Ein Vergleich zwischen Österreich, Slowakei und Deutschland. In: Controller Magazin, Arbeitsergebnisse aus der Controller-Praxis. Vol. 41. Iss. 5. p. 49-54. ISSN 1616-0495

Malé a stredné podnikanie v číslach. (2017). Bratislava: Slovak Business Agency. [Web blog post]. Retrieved from http://www.sbagency.sk/sites/default/files/image/msp_v_cislach_v_roku_2016_final_v_20_10_2017_002.pdf

Mikušová, M. (2014). Krízový management pro malé a střední podniky. Bratislava: Wolters Kluwer. ISBN 978-80-8168$106-6$

Zapletalová, Š. et al. (2012). Krízový management podniku pro 21. století. Praha: Ekopress. ISBN 978-80-86929-85-9

Šimák, L. (2006). Manažment rizík. Žilina: EDIS. [Web blog post]. Retrieved from

http://fsi.uniza.sk/kkm/old/publikacie/mn_rizik.pdf 